Title:
Author(s):

FIRST REPORT ON NON-THERMAL PLASMA REACTOR SCALING CRITERIA AND OPTIMIZATION MODELS

\section{RECEIVID \\ MAY 281998 \\ OSTI}

Louis A. Rosocha, CST-18

Richard A. Korzekwa, CST-18

Submitted to:

Strategic Environmental Research \& Development Program (SERDP) Office and to be made available for public release. 


\section{DISCLAIMER}

This report was prepared as an account of work sponsored by an agency of the United States Government. Neither the United States Government nor any agency thereof, nor any of their employees, makes any warranty, express or implied, or assumes any legal liability or responsibility for the accuracy, completeness, or usefulness of any information, apparatus, product, or process disclosed, or represents that its use would not infringe privately owned rights. Reference herein to any specific commercial product, process, or service by trade name, trademark, manufacturer, or otherwise does not necessarily constitute or imply its endorsement, recommendation, or favoring by the United States Government or any agency thereof. The views and opinions of authors expressed herein do not necessarily state or reflect those of the United States Government or any agency thereof. 


\title{
First Report on Non-Thermal Plasma Reactor Scaling Criteria and Optimization Models
}

\author{
Prepared under Strategic Environmental Research \& Development Program (SERDP) \\ Compliance Project CP-1038: Development of Non-Thermal Plasma Reactor \\ Technology for Control of Atmospheric Emissions
}

\author{
Louis A. Rosocha \\ Principal Investigator \\ and \\ Richard A. Korzekwa \\ Los Alamos National Laboratory \\ January 13,1998
}

\section{Introduction}

The purpose of SERDP project CP-1038 is to evaluate and develop non-thermal plasma (NTP) reactor technology for Department of Defense (DoD) air emissions control applications. The primary focus is on oxides of nitrogen $\left(\mathrm{NO}_{\mathrm{x}}\right)$ and a secondary focus on hazardous air pollutants (HAPs), especially volatile organic compounds (VOCs). Example $\mathrm{NO}_{\mathrm{x}}$ sources are jet engine test cells (JETCs) and diesel-engine powered electrical generators. Example VOCs are organic solvents used in painting, paint-stripping, and parts cleaning.

To design and build NTP reactors that are optimized for particular DoD applications, one must understand the basic decomposition chemistry of the target compound(s) and how the decomposition of a particular chemical species depends on the air-emissions stream parameters and the reactor operating parameters. This report is intended to serve as an overview of the subject of reactor scaling and optimization and will discuss the basic decomposition chemistry of nitric oxide (NO) and two representative VOCs, trichloroethylene and carbon tetrachloride, and the connection between the basic plasma chemistry, the target species properties, and the reactor operating parameters (in particular, the operating plasma energy density). System architecture, that is how NTP reactors can be combined or ganged to achieve higher capacity, will also be briefly discussed.

A companion report, which deals with further aspects on the development of reactor-scaling algorithms and discusses a test-case hybrid-reactor system, has been completed under a subcontract managed by our Army Research Laboratory (ARL) team member Dr. Andrzej Miziolek. That project report is entitled "Development of Scaling and Economic-Evaluation Algorithms for Non-Thermal Plasma Reactors for Control of $\mathrm{NO}_{\mathrm{x}}$ Emissions," and was produced by M. Matsuoka, S.J. Kim, P.C. Looy, and Prof. J.S. Chang of McMaster University (October 27, 1997). 
In other SERDP-related work, economic projections for a pulsed corona discharge de- $\mathrm{NO}_{\mathrm{x}}$ system for full-scale operation of Jet Engine Test Cells (JETCs) have been presented by S.M. Haythornthwaite, M.D. Durham, D. Rugg, and J.D. Wander in a report from ADA Technologies entitled "Application of Pulse-Corona-Induced Plasma to Jet Engine Test Cells." (under a contract managed by Dr. Joseph Wander of the Armstrong Laboratory).

\section{Representative Non-Thermal Plasma Reactors}

Figure 1 shows example NTP reactors for gas-phase pollutant processing $[1,2]$. In an electrical discharge, a high voltage is applied across electrodes in the gas or along a surface adjacent to the gas. An electron-beam reactor requires an electron accelerator to produce the energetic electron beam $(\sim 100 \mathrm{keV}-1 \mathrm{MeV})$ that is injected into the process gas. The energetic plasma electrons are responsible for pollutant decomposition, either through direct electron collisions or indirectly through the creation of free radicals that attack the pollutants.

The three electric-discharge reactors - silent discharge (dielectric barrier), pulsed corona, and electrified packed bed all create transient electrical-discharge streamers in the gas. The streamer is the source of energetic electrons and other active species. A relatively high voltage (determined by the reactor geometry, gas composition, and gas pressure) is required to cause electrical breakdown in the gas. The necessary voltage is supplied by a drive circuit connected to the reactor. In corona, a non-homogeneous electric field is used to stabilize the discharge and prevent thermal arc formation. Silent discharges use charge buildup on a capacitive barrier to achieve a similar end result. An electrified packed bed is closely related to a barrier discharge. A surface-discharge reactor (not shown), which uses streamers across a dielectric surface, is similar to both the dielectric barrier and electrified packed bed reactors. Streamers can be thought of as cylindrical current filaments with typical radius $\sim 100 \mu \mathrm{m}$. They are transient discharges (e.g., lasting only a few nanoseconds for oxygen or air), fed by ionization and detachment and then arrested when the electric field is reduced to the point where electron attachment becomes dominant. For streamers in pure oxygen and air, the average electron energy and electron density are $\mathrm{T}_{\mathrm{e}} \sim 3-5 \mathrm{eV},[\mathrm{e}] \sim 10^{14} / \mathrm{cm}^{3}$, while a typical breakdown reduced electric field strength in the gas is $\mathrm{E} / \mathrm{N} \sim 100-200 \mathrm{Td}$. Multiple streamers typically give accumulated plasma energy loadings of $10 \mathrm{~s}-1,000 \mathrm{~s} \mathrm{~J} / \mathrm{liter}$-atm [2].

In an electron-beam reactor, the source of electrons (the cathode) can be separate from the accelerating-field section (as in thermionic-cathode and plasma-cathode devices) or integrated with the accelerating-field section (as in a field-emission-cathode electron gun). Electron-beam reactors must use a foil or window to separate the vacuum section of the accelerator from the process gas. The electron beam penetrates the foil, depositing energy in the process gas by collisions and molecular excitation processes coupled to the creation of a large-volume nonthermal plasma. For typical electron-beam reactors, the mean electron energies can be much larger than those for discharge reactors (e.g., $\sim 10 \mathrm{eV}$ for electron-beam, as compared to $\sim$ few $\mathrm{eV}$ for discharges). Similar energy loadings can usually be obtained in both types of reactors. 


\section{Basic Decomposition Chemistry}

Plasma-generated active species (radicals and secondary electrons) are the initiators of pollutant decomposition reactions [1,2]. Two major decomposition channels for a gas-phase chemical pollutant $\mathrm{X}$ are direct electron impact or chemical (radical-promoted) attack:

$$
\begin{aligned}
& \mathrm{e}+\mathrm{X} \rightarrow \text { products } \\
& \mathrm{O}, \mathrm{OH}+\mathrm{X} \rightarrow \text { products. }
\end{aligned}
$$

The first path is expected to dominate at large contaminant concentrations (when a higher energy fraction is absorbed by the pollutant), while the second should dominate at smaller concentrations.

The decomposition chemistry for NO is tractable and largely described as follows [1]:

$$
\begin{aligned}
& \mathrm{O}+\mathrm{NO}+\mathrm{M} \rightarrow \mathrm{NO}_{2}+\mathrm{M} \\
& \mathrm{OH}+\mathrm{NO}_{2}+\mathrm{M} \rightarrow \mathrm{HNO}_{3}+\mathrm{M} \\
& \mathrm{O}+\mathrm{NO}_{2} \rightarrow \mathrm{NO}+\mathrm{O}_{2} \\
& \mathrm{~N}+\mathrm{NO} \rightarrow \mathrm{N}_{2}+\mathrm{O} \\
& \mathrm{N}+\mathrm{NO}_{2} \rightarrow \mathrm{N}_{2} \mathrm{O}+\mathrm{O} .
\end{aligned}
$$

Oxidative-mode reactions involving $\mathrm{O}$-atoms can trap total $\mathrm{NO}_{\mathrm{x}}$ as $\mathrm{NO}$ and $\mathrm{NO}_{2}$. Oxidativemode reactions involving $\mathrm{OH}$-radicals produce nitric acid $\mathrm{HNO}_{3}$, which can be easily removed by a caustic scrubber. Reductive-mode reactions involving $\mathrm{N}$-atoms instead drive more $\mathrm{NO}_{\mathrm{x}}$ to $\mathrm{N}_{2}$ and $\mathrm{O}_{2}$ but require higher energy electrons.

With oxidative de- $\mathrm{NO}_{\mathrm{x}}$ processes driven by O-atoms, $\mathrm{NO}_{2}$ is the most probable reaction intermediate. It is somewhat more soluble in water than $\mathrm{NO}_{\mathrm{x}}$, which facilitates its removal by conventional wet-scrubbing techniques. However, for higher flow rates, the scrubber is usually impracticably large. The chemistry can be favorably influenced by multiple excitation, in which two or more NTP reactors are placed in series with scrubbers. Here the $\mathrm{NO}_{2}$ reaction intermediate is scrubbed out at a low concentration before the gas is treated by the next reactor, thus reducing the conversion back to NO.

In wet gas (most representative of practical off-gas conditions), conversion to caustic-scrubbable nitric acid $\left(\mathrm{HNO}_{3}\right)$ is probably the most practical de- $\mathrm{NO}_{x}$ pathway. In a scrubber, nitric acid can also be converted to potentially useful byproducts, such as ammonium nitrate $\mathrm{NH}_{4} \mathrm{NO}_{3}$ agricultural fertilizer, by adding ammonia $\mathrm{NH}_{3}$. With humid gas, nitrous acid $\mathrm{HNO}_{2}$ is also a significant reaction intermediate, which may decompose into $\mathrm{NO}$ and $\mathrm{NO}_{2}$. Multiple excitation, accompanied by intermediate filtration can probably also reduce such undesirable reformation of $\mathrm{NO}_{\mathrm{x}}$.

The addition of ammonia can also be used to advantage in further promoting reductive chemistry [1], as exemplified by the following reactions: 


$$
\begin{aligned}
& \mathrm{OH}+\mathrm{NH}_{3} \rightarrow \mathrm{NH}_{2}+\mathrm{H}_{2} \mathrm{O} \\
& \mathrm{NH}_{2}+\mathrm{NO} \rightarrow \mathrm{N}_{2}+\mathrm{H}_{2} \mathrm{O} \\
& \mathrm{NO}_{2}+\mathrm{NH}_{2} \rightarrow \mathrm{N}_{2} \mathrm{O}+\mathrm{H}_{2} \mathrm{O},
\end{aligned}
$$

where the oxidative radical $\mathrm{OH}$ is replaced by the reductive radical $\mathrm{NH}_{2}$.

There is some evidence in the literature to suggest that hydrocarbon additives can improve the efficiency of $\mathrm{NO}_{\mathbf{x}}$ removal by regenerating $\mathrm{OH}$-radicals. This is illustrated by the following reaction scheme using methane $\left(\mathrm{CH}_{4}\right)$ as a representative hydrocarbon.

$$
\begin{aligned}
& \mathrm{OH}+\mathrm{CH}_{4} \rightarrow \mathrm{H}_{2} \mathrm{O}+\mathrm{CH}_{3} \\
& \mathrm{CH}_{3}+\mathrm{O}_{2}+\mathrm{M} \rightarrow \mathrm{CH}_{3} \mathrm{O}_{2}+\mathrm{M} \\
& \mathrm{CH}_{3} \mathrm{O}_{2}+\mathrm{NO} \rightarrow \mathrm{CH}_{3} \mathrm{O}+\mathrm{NO}_{2} \\
& \mathrm{CH}_{3} \mathrm{O}+\mathrm{O}_{2} \rightarrow \mathrm{HCHO}+\mathrm{HO}_{2} \\
& \mathrm{HO}_{2}+\mathrm{NO} \rightarrow \mathrm{NO}_{2}+\mathrm{OH} .
\end{aligned}
$$

Experiments on pulsed corona performed at the Lawrence Livermore National Laboratory have provided corroboration of such effects by showing that the addition of n-octane $\left(\mathrm{C}_{8} \mathrm{H}_{18}\right)$ improves the efficiency of NO removal [3].

Conventional de- $\mathrm{NO}_{x}$ technologies generally employ thermal-catalytic processes, scrubbing, and/or the addition of chemical additives (e.g., hydrocarbons, ammonia, urea compounds, isocyanic acid). The attractiveness of NTP-based technologies is the ability to initiate $\mathrm{NO}_{\mathrm{x}}$ removal chemistry similar to that of conventional process by employing electricity-based, selective chemistry (that might greatly reduce or even eliminate the need for large-scale chemical scrubbers).

Other molecules, like many VOCs, will often undergo a series of more complicated reactions before the final products result. The decomposition of a chlorocarbon like trichloroethylene is dominated by free-radical reactions at the relatively high $\mathrm{E} / \mathrm{N}$ of electric discharges $[4,5]$

$$
\mathrm{O}\left({ }^{3} \mathrm{P}\right) \text { or } \mathrm{OH}+\mathrm{C}_{2} \mathrm{HCl}_{3} \rightarrow \mathrm{CO}_{2}+\mathrm{HCl}+\mathrm{Cl}_{2}+\mathrm{COCl}_{2}+\ldots
$$

Strong electron attachers (e.g., $\mathrm{CCl}_{4}$ ) are preferentially decomposed by dissociative electron attachment at low E/N $[6,7]$

$$
\begin{aligned}
& \mathrm{e}+\mathrm{CCl}_{4} \rightarrow \mathrm{CCl}_{3}+\mathrm{Cl}^{-} \\
& \mathrm{CCl}_{3}+\mathrm{O}_{2} \rightarrow \mathrm{COCl}_{2}+\mathrm{Cl}+\mathrm{ClO} .
\end{aligned}
$$

Decomposition is not necessarily complete treatment - the goal is to produce less toxic or more easily managed final products. Byproducts must also be considered (e.g., $\mathrm{COCl}_{2}$ is toxic but is easily removed by reactions with water). In laboratory studies, the degree of decomposition and treatment byproducts are measured with an instrument like a gas chromatograph - mass spectrometer or a set of combustion gas analyzers (CGAs), which may include a chemiluminescence detector for $\mathrm{NO}_{\mathrm{x}}$. 
A key advantage of NTP processing is the ability to simultaneously remove multiple pollutants (e.g., several species of VOCs or VOCs in combination with $\mathrm{NO}_{\mathrm{x}}$ and/or $\mathrm{SO}_{\mathrm{x}}$ ). The detailed plasma-initiated removal chemistry of a particular compound or mixture of compounds can be quite complicated and will not be further addressed in this report.

\section{Decomposition-Scaling Relationships}

In many non-thermal plasma devices (like gas lasers, ozonizers, etc.,), a key process parameter is the specific energy (plasma energy density) deposited in the gas. This is also true for the decomposition of a pollutant in an NTP reactor. Experiments with various reactors have shown that the degree of removal of a particular contaminant depends on the applied plasma energy density $\bar{E}$, a characteristic energy-density parameter (which is related to the target compound), the carrier gas, and the reduced electric field $\mathrm{E} / \mathrm{N}$ for the reactor $[1,2,6]$.

Recent work on comparing different aqueous-phase advanced oxidation processes (AOPs) has shown that simple overall kinetic models can be used to describe the rate of radical-initiated decomposition of a target species [8]. Using an analogous description for a gas-phase AOP based on an NTP process, one can write the following expression for the decomposition of pollutant $\mathrm{X}$ in the presence of radical scavengers $S_{i}$

$$
\frac{d[X]}{d t}=-\frac{G \overline{\mathrm{P}} k[X]}{k[X]+\sum_{i} k_{S_{i}}\left[S_{i}\right]},
$$

where $[\mathrm{X}]$ is the pollutant concentration, $\mathrm{G}$ is the radical production efficiency, $\overline{\mathrm{P}}$ is the plasma power density, $\mathrm{k}$ is the radical-pollutant kinetic rate constant, $\left[\mathrm{S}_{\mathrm{i}}\right]$ is concentration of the $\mathrm{i}^{\text {th }}$ scavenger, and $\mathrm{k}_{\mathrm{Si}}$ is the scavenging rate constant for the $\mathrm{i}^{\text {th }}$ species.

Assuming an idealized reactor (constant $\mathrm{E} / \mathrm{N}$ and carrier gas temperature), given the scavenger concentrations, and making the substitution $\bar{P}=d \bar{E} / d t$, one can integrate the above equation to get the pollutant concentration $[\mathrm{X}]$ as a function of the starting concentration $[\mathrm{X}]_{0}$ and the specific energy. When the rate of radical-pollutant attack $k[\mathrm{X}]$ is small compared to the rate of radical scavenging $\Sigma_{\mathrm{i}} \mathrm{k}_{\mathrm{Si}}\left[\mathrm{S}_{\mathrm{i}}\right]$, the pollutant decomposition can be ideally expressed as

$$
[\mathrm{X}]=[\mathrm{X}]_{0} \exp (-\bar{E} / \beta),
$$

where $[\mathrm{X}]_{0}$ is the initial pollutant concentration, $[\mathrm{X}]$ is the resulting concentration, $\bar{E}$ is the applied specific energy (or plasma power divided by gas flow rate, $\mathrm{P} / \mathrm{Q}$ ), and $\beta$ is the e-fold energy density

$$
\beta=\frac{\sum_{i} k_{S_{i}}\left[S_{i}\right]}{k G} .
$$

Supplying one $\beta$ to the reactor reduces the concentration by $1 / \mathrm{e}, 2 \beta$ by $1 / \mathrm{e}^{2}$, and so on. In this ideal case, when $-\ln \left([\mathrm{X}] /[\mathrm{X}]_{0}\right)$ is plotted versus $\overline{\mathrm{E}}$, a straight line of slope $1 / \beta$ results. For real cases, the plot is not necessarily a straight line, so such a slope-determined $\beta$-value is only an 
approximation. In some cases, the removal function can additionally depend on the initial pollutant concentration. Figure 2 presents example decomposition data for two representative compounds, the flue gas nitric oxide (NO) and the chlorinated hydrocarbon trichloro-ethylene (TCE), $\mathrm{C}_{2} \mathrm{HCl}_{3}$. The removal versus specific energy plots for neither of these two compounds shows a very strong dependence on initial concentration.

The $\beta$-value links the generation of radicals through gaseous electronics/plasma chemistry (Gvalues) with their utilization through the decomposition chemistry. The G-value is a function of an effective rate constant for radical generation $\mathrm{k}_{\mathrm{rad}}$ (e.g., the dissociation rate constant for dissociating $\mathrm{O}_{2}$ molecules into $\mathrm{O}$-atoms), the electron drift velocity $\mathrm{v}_{\mathrm{d}}$, and the reduced electric field strength $\mathrm{E} / \mathrm{N}$

$$
G=f\left(\frac{k_{r a d}}{\mathbf{v}_{d} \frac{E}{N}}\right) .
$$

The rate constant $\mathrm{k}_{\mathrm{rad}}$ and the drift velocity $\mathrm{v}_{\mathrm{d}}$ also depend on the reduced field $\mathrm{E} / \mathrm{N}$ (electron temperature), so the $\beta$-value essentially depends on $E / \mathrm{N}$ and the chemical kinetics.

\section{Reactor Scaling Concepts}

The specific energy can also be expressed as

$$
\overline{\mathrm{E}}=\mathrm{P} / \mathrm{Q}=\overline{\mathrm{P}} \tau_{\mathrm{r}},
$$

where $\mathrm{P}$ and $\mathrm{Q}$ are the plasma power and gas flow rate, respectively, $\overline{\mathrm{P}}$ is the power density (power per unit volume) and $\tau_{\mathrm{r}}$ is the residence time of a unit volume of gas in the active portion of the reactor.

To increase the removal fraction $[\mathrm{X}] /[\mathrm{X}]_{0}$ for a given gas mixture, the specific energy $\overline{\mathrm{E}}$ must be increased. $\bar{E}$ can be increased by either increasing $\bar{P}$ or $\tau_{r}$ (or, equivalently, decreasing the flow rate $\mathrm{Q}$ for a given cell volume). Assume the reactor volume is kept fixed. Therefore, to increase the removal fraction at a fixed flow rate, one can directly increase the power to the reactor. To increase the removal fraction at a fixed power, one can decrease the gas flow rate.

For a given reactor, the power and gas flow cannot be arbitrarily increased. Limits such as gasflow impedance or heat conduction out of the reactor may limit the practical size of the reactor in terms of how much gas flow or deposited power can be achieved.

Additionally, the power density $\overline{\mathrm{P}}$ depends on the particular type of reactor being employed. Typically-achieved power densities for pulsed corona, dielectric-barrier, and electron-beam reactors are $<15 \mathrm{~mW} / \mathrm{cm}^{3}, 1 \mathrm{~W} / \mathrm{cm}^{3}$, and $2.5 \mathrm{~W} / \mathrm{cm}^{3}$, respectively [9]. Because of the lower spatial density of electrical discharges (smaller active volume compared to total gas volume) in pulsed corona reactors (PCRs), PCRs achieve a much smaller power density than dielectric- 
barrier and electron-beam reactors. This implies a much smaller energy density at a given gas residence time.

\section{Reactor Architectures}

In the context of this report, architecture refers to the manner in which a NTP reactor, or combination of reactors and other equipment is configured to treat an emissions stream. At present, we assume that we will mainly deal with end-of-pipe emissions treatment (right before discharge to the air) for the DoD. The simplest end-of-pipe architecture is to employ an NTP reactor (or array) as a stand-alone emissions control device. Two basic reactor scaling architectures are discussed below: simply increasing the size of a single reactor (monolithic scaling) and parallel or ganged connection of smaller reactors (modular scaling).

\section{Monolithic Scaling}

To increase the capacity of an NTP reactor, we need to increase the gas flow rate. At a fixed removal fraction, the power must be increased in proportion to the flow rate. That is, if we scale up the flow by a factor $\mathrm{N}_{\mathrm{s}}$ the power must be scaled up by the same factor to keep the energy density fixed $\left(\mathrm{N}_{s} \mathrm{P} / \mathrm{N}_{\mathrm{s}} \mathrm{Q}=\mathrm{P} / \mathrm{Q}\right)$. This represents monolithic scaling, where we simply increase the physical size of the reactor while proportionally increasing the gas flow rate and plasma power.

\section{Modular Scaling}

Alternatively, the total gas flow and total plasma power can be divided among several reactor modules that are connected in parallel. The power to each reactor is then $\mathrm{P} / \mathrm{N}_{\mathrm{s}}$ while the gas flow rate is $\mathrm{Q} / \mathrm{N}_{\mathrm{s}}$ (which keeps a constant energy density $\mathrm{P} / \mathrm{N}_{\mathrm{s}} / \mathrm{Q} / \mathrm{N}_{\mathrm{s}}=\mathrm{P} / \mathrm{Q}$ ). This represents modular scaling, whereby a reactor module of desirable properties is replicated many times, is quite attractive. Such modularization scaling of silent discharge cells has been previously demonstrated for the industrial-scale synthesis of ozone, where municipal water treatment plants frequently require the on-site generation of thousands of kilograms per day.

The modular approach has been employed at Los Alamos for scaling up both laboratory-scale and small, field-pilot-scale units. Typically, rectangular electrode-area, dielectric-barrier (silent discharge) reactors have been employed for VOC treatment tests $[10,11]$. However, for systems requiring the treatment of higher temperature (e.g., $>100 \mathrm{C}$ ) emissions streams (sources of $\mathrm{NO}_{\mathrm{x}}$ sources such as engines, etc.), cylindrical reactor cells may be more robust and practical in an engineering sense. Figure 3 illustrates a parallel array of dielectric-barrier plasma cells constructed of ceramic tubes with metalized electrodes, capable of elevated temperature operation. The summary results of electrical-performance characterization tests on a single module, which is a prototype for such an array, are presented in the Appendix.

However, because NTP reactors can be power intensive, neither monolithic nor modular reactors may be the most economic or practically-feasible architecture for very high flow applications. In that case, it might be better to consider yet another type of architecture, namely hybrid systems: an NTP reactor subsystem (or set of reactors) is combined with an absorber or catalytic subsystem. These concepts will not be further discussed here, but are the subject of another report entitled "Feasibility Analysis Report for Hybrid Non-Thermal Plasma Reactors". 


\section{Figure of Merit and Optimization}

Optimizing the performance (degree of removal of the pollutant, decomposition products, energy consumption, etc.) of an NTP reactor is a complicated process. NTP processing is usually quite energy intensive. Therefore, in this section, we will concentrate on a discussion of reactor electrical energy consumption, because preliminary economic analysis indicates that the major cost of an NTP reactor system resides in the cost of the electrical power supply, assuming one uses readily-available power supplies - which are usually not well-matched to a plasma load. In some cases the power supply might be $75-90 \%$ of the plasma reactor cost. This cost is expected to fall with the development of better-matched, state-of-the-art power supplies and operation of the plasma reactor at more optimal treatment conditions.

A useful figure of merit for the decomposition of pollutants is defined by the energy delivered to the plasma per hazardous molecule removed from the gas stream. At any instant, this can be expressed as the following quantity obtained by solving Equation 2 for $\bar{E}$ and taking the derivative:

$$
\gamma_{i}=-\frac{d \overline{\mathrm{E}}}{d[X]}=-\frac{d\left[-\beta \ln \left(\frac{[X]}{[X]_{0}}\right)\right]}{d[X]}=\frac{\beta}{[X]}
$$

This is the instantaneous energy cost per molecule removed; a more practically-useful parameter is the integral, or average, energy $\operatorname{cost} \gamma$

$$
\gamma=\frac{\overline{\mathrm{E}}}{[X]_{0}-[X]}=\frac{-\beta \ln \left(\frac{[X]}{[X]_{0}}\right)}{[X]_{0}\left(1-\frac{[X]}{[X]_{0}}\right)}
$$

Here, the energy cost per molecule is expressed in terms of the $\beta$-value, the degree of removal, and the initial concentration. As an example, Figure 4 gives $\bar{E}, \gamma$, and the reciprocal of $\gamma, G$ (number of molecules removed per $100 \mathrm{eV}$ of deposited energy) for a model TCE mixture. The $\gamma$-value translates into an actual electrical energy cost for the process. Another convenient unit for the figure of merit is the number of kilowatt-hours required to remove a kilogram of hazardous compound (i.e., $\mathrm{kW}$-hr $/ \mathrm{kg}$ ). For a $\gamma$-value of $50 \mathrm{eV} /$ molecule, approximately $10 \mathrm{~kW}$ $\mathrm{hr} / \mathrm{kg}$ of TCE are required. At an electrical energy cost of $5 \phi / \mathrm{kW}-\mathrm{hr}$, TCE removal costs about $50 \notin$ per $\mathrm{kg}$ (based only on the cost of energy into the plasma and neglecting other efficiency factors like that for the power supply and the cost of ancillary equipment).

Recently-presented work [12] on the fundamental limits for the removal of NO from engine exhaust gases, based on gaseous electronics and plasma chemistry considerations, has shown that the energy costs are $40 \mathrm{eV} / \mathrm{NO}$ molecule when reductive chemistry dominates and $18 \mathrm{eV} / \mathrm{NO}$ molecule when oxidative chemistry is dominant. Using the $\gamma$-value of $18 \mathrm{eV} /$ molecule, approximately $15.7 \mathrm{~kW}$-hr $/ \mathrm{kg}$ NO removed are required. At the $5 \phi / \mathrm{kW}$-hr electrical cost figure, the NO-removal electrical cost is about $79 \mathrm{c} / \mathrm{kg}$. It should be noted that the oxidative channel 
principally results in the conversion of $\mathrm{NO}$ to $\mathrm{NO}_{2}$, which does not change the total $\mathrm{NO}_{\mathrm{x}}$ concentration a great deal. The reductive channel, which leads to $\mathrm{N}_{2}+\mathrm{O}_{2}$ is preferable because less ancillary equipment (like an $\mathrm{NO}_{2}$ trap/scrubber) is required in the de- $\mathrm{NO}_{\mathrm{x}}$ system.

What Equation 6 tells us is that the instantaneous energy cost per pollutant molecule removed is lower when the pollutant concentration is high. This makes intuitive sense because, at high concentration, active species always have a high probability of reacting with a target molecule.

Equation 7 tells us that the average energy cost per removed molecule is lower at lower degrees of pollutant removal. In optimizing reactor performance, one can conceive of somehow adjusting the active species concentrations so that the ratio of pollutant concentration to activespecies concentration is always relatively large. This way the probability of attack is high, while both the specific energy $\bar{E}$ and the degree of removal $\left([\mathrm{X}] /[\mathrm{X}]_{0} \sim 1\right)$ are low.

Two possible ways of achieving this optimization are constructing a continuous-flow reactor whose energy density decreases as the residence time of the treated gas in the reactor increases or constructing a serial train of reactors, each having optimal plasma energy density. One might even construct the first reactor such that it contains individual, segmented excitation regions (like a serial train within a single reactor).

\section{Summary and Conclusions}

The largest share of the present body of technical literature describing the treatment of air emissions with non-thermal plasmas (NTPs) mainly presents phenomenological descriptions of NTP reactor performance and, consequently in most cases, does not provide a consistent way to compare and/or predict the scaling and optimization properties of different NTP reactors. In this report, we have attempted to present a simple basis for comparing different types of NTP reactors, based on the concept of the plasma specific energy (electrical energy per unit volume deposited in the reactor active volume) required to remove a particular pollutant to a prescribed level in a defined exhaust-gas mixture.

It should be emphasized that NTP is an emerging air-emissions control technology. Very few (if any) commercial systems exist. Also, for many emissions applications, the present forms of NTP technology are expected to be expensive (in terms of electrical power consumption) and ancillary equipment (e.g., scrubbers) that may be necessary to handle treatment byproducts. Realizing the performance and economic shortcomings of stand-alone NTP reactors, some workers in this discipline have proposed the use of staged or hybrid systems to better match particular airemissions control applications. In this case, overall system scaling must be considered in terms of the separate parts of the emissions-control system - that is the NTP reactor itself and the other major components. In this report, we have focused on the scaling and optimization concepts for the NTP part for two reasons: so that we can at least provide a simple means of making a firstorder comparison of different NTP reactors and because the NTP part of the system is usually perceived to be the less mature and most expensive part. Comparing different hybrid systems is considerably more complicated and will not be treated in this report. 
Using the additional concepts of monolithic and modular reactor scaling, we then have a relatively simple means of predicting how one can increase the capacities (exhaust-gas flow rate or amount of pollutants treated) of different types of NTP reactors and how one can estimate the energy use/cost associated with the scaled-up reactor.

A figure of merit (the energy cost per pollutant molecule removed) has been introduced and we have shown how this figure of merit is related to some basic NTP reactor performance criteria namely the plasma specific energy $\bar{E}$ and the degree of pollutant removal, frequently expressed as $\ln \left([\mathrm{X}] /[\mathrm{X}]_{0}\right)$. The figure of merit is the same for either a monolithic or modular NTP reactor. However, the overall system cost scaling is likely to be very different for each of these types of scaling methodologies (and should be treated in a future report on system economics).

This report has served as an introduction to some basic scaling and optimization concepts - future reports (and the existing companion report from McMaster University) will further explore these concepts for particular reactors and reactor systems and architectures.

\section{References}

1. See articles in Non-Thermal Plasma Techniques for Pollution Control, NATO ASI Series, Vol. G34, Parts $A \& B$, edited by B.M. Penetrante and S.E. Schultheis, Springer-Verlag, Berlin \& Heidelberg (1993).

2. L.A. Rosocha, "Processing of Hazardous Chemicals Using Silent Electrical Discharge Plasmas," Chapter 11 in Environmental Aspects in Plasma Science, edited by W. Manheimer, L.E. Sugiyama, and T.H. Stix, American Institute of Physics Press, Woodbury, NY (1997).

3. G.E. Vogtlin, J.N. Bardsley, K.E. Freytag, B.M. Penetrante, and P.A. Vitello, "Non-Thermal Discharge Processing of Gaseous Pollutants," Proceeding of First International EPRI/NSF Symposium on Advanced Oxidation, EPRI TR-102927-V2 (1993).

4. D. Evans, L.A. Rosocha, G.K. Anderson, J.J. Coogan and M.J. Kushner, "Plasma remediation of trichloroethylene in silent discharge plasmas", J. Appl. Phys. 74 (9), pp. 5378-5386 (1993).

5. Z. Falkenstein, "Fundamental Studies on the Combined (V)UV-Non-Thermal-Plasma Treatment of Air Pollutants," Thesis, University of Karlsruhe \& Los Alamos National Laboratory, LA-UR-96-2219 (July 1996).

6. B.M. Penetrante, M.C. Hsiao, J.N. Bardsley, B.T. Merritt, G.E. Vogtlin, P.H. Wallman, A. Kuthi, C.P. Burkhart, and J.R. Bayless, "Electron beam and pulsed corona processing of carbon tetrachloride in atmospheric pressure gas streams," Physics Lett. A209, pp. 69-77 (1995).

7. D.G. Storch, M.B. Chang, M.J. Rood, and M.J. Kushner, "Modeling and diagnostics of dielectric barrier discharge destruction of $\mathrm{CCl}_{4}$, "Unpublished progress report to Los Alamos National Laboratory (1991).

8. J.R. Bolton, K.G. Bircher, W. Tumas, and C.A. Tolman, "Figures-of-Merit for the Technical Development and Application of Advanced Oxidation Processes," Journal of Advanced Oxidation Technologies, 1, pp. 13-17 (1996). 
9. L.A. Rosocha, "Non-Thermal Plasmas as Gas-Phase Advanced Oxidation Processes," presented at Second International Symposium on Non-Thermal Plasma Technology for Pollution Control, Salvador, Brazil (August 11-15, 1997).

10. L.A. Rosocha, J.J. Coogan, R.A. Korzekwa, D.A. Secker, R.F. Riemers, P.G. Herrmann, P.J. Chase, M.P. Gross, and M.R. Jones, "Field Demonstration and Commercialization of Silent Discharge Plasma Air Pollutant Control Technology", Proceedings of 2nd International EPRI/NSF Symposium on Environmental Applications of Advanced Oxidation Technologies, pp. (Section 5) 107-121, Electric Power Research Institute (September 1997).

11. J.J. Coogan, A.S. Jassal, "Silent Discharge Plasma (SDP) for Point-of-Use (POU) Abatement of Volatile Organic Compound (VOC) Emissions: Final Report (ESHC003)", SEMATECH Report 97023244A-ENG (February 1997).

12. B.M. Penetrante, "Fundamental Limits on Chemical Reduction of $\mathrm{NO}_{\mathrm{x}}$ by Non-Thermal Plasmas," presented at Second International Symposium on Non-Thermal Plasma Technology for Pollution Control, Salvador, Brazil (August 11-15, 1997).

13. O. Wolf et al, "Experimental Investigations of the Removal of Toxic Exhaust Gas Components by Dielectric Barrier Discharges," Proceedings of 7th Bundesdeutsche Fachtagung für Plasmatechnologie (BFPT-7), Poster P 85, (1996). 


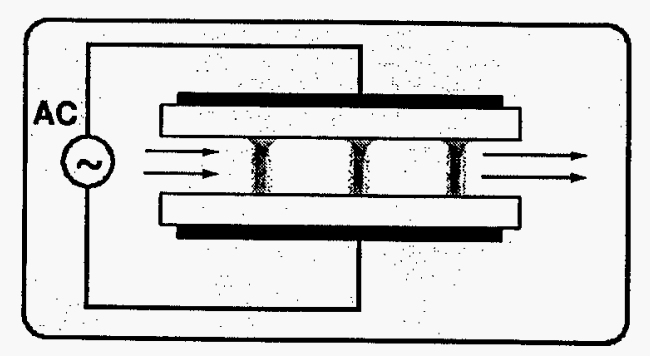

Silent discharge (dielectric-barrier discharge)

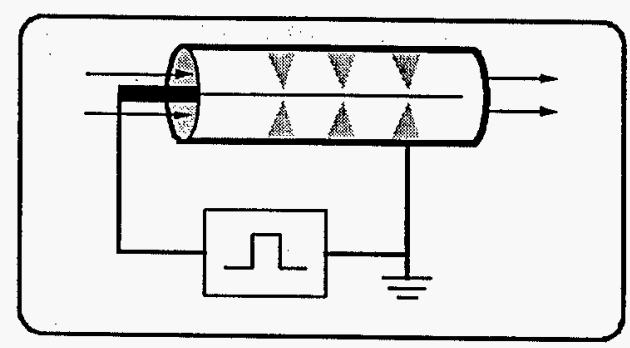

Pulsed or DC corona

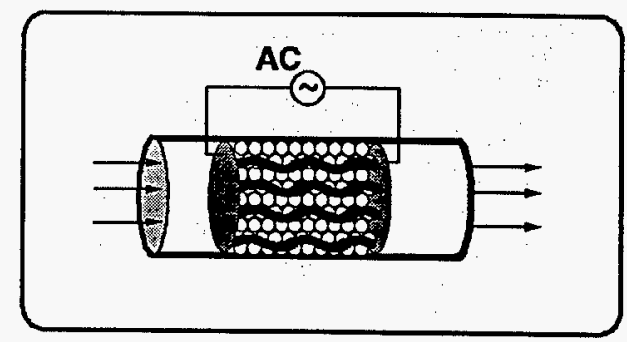

Electrified packed bed

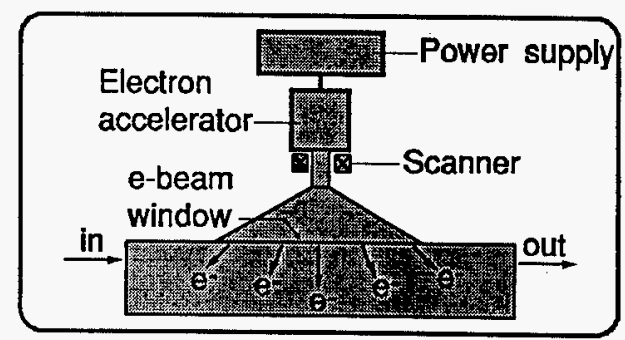

Electron beam

Figure 1: Commonly-employed NTP reactors.

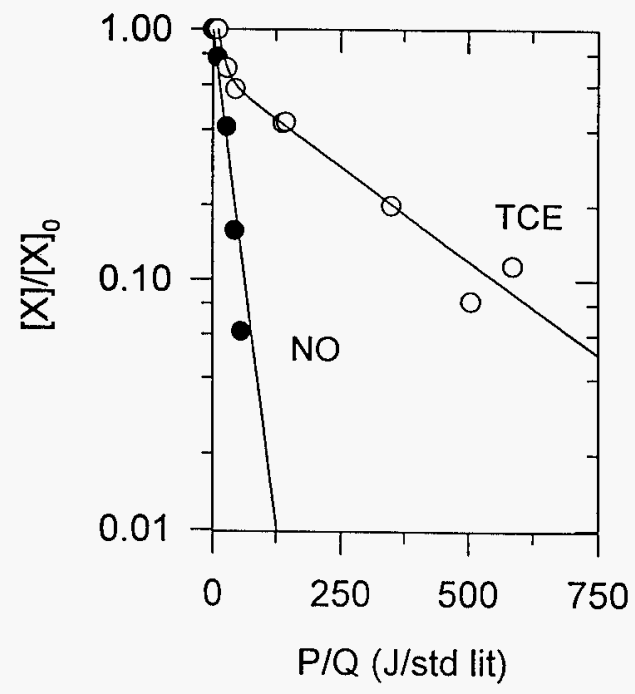

Figure 2: Decomposition plots for $400 \mathrm{ppm}$ NO in simulated engine-exhaust gas after Wolf et al [13] and 190 ppm TCE in humid air after Falkenstein [5]. 


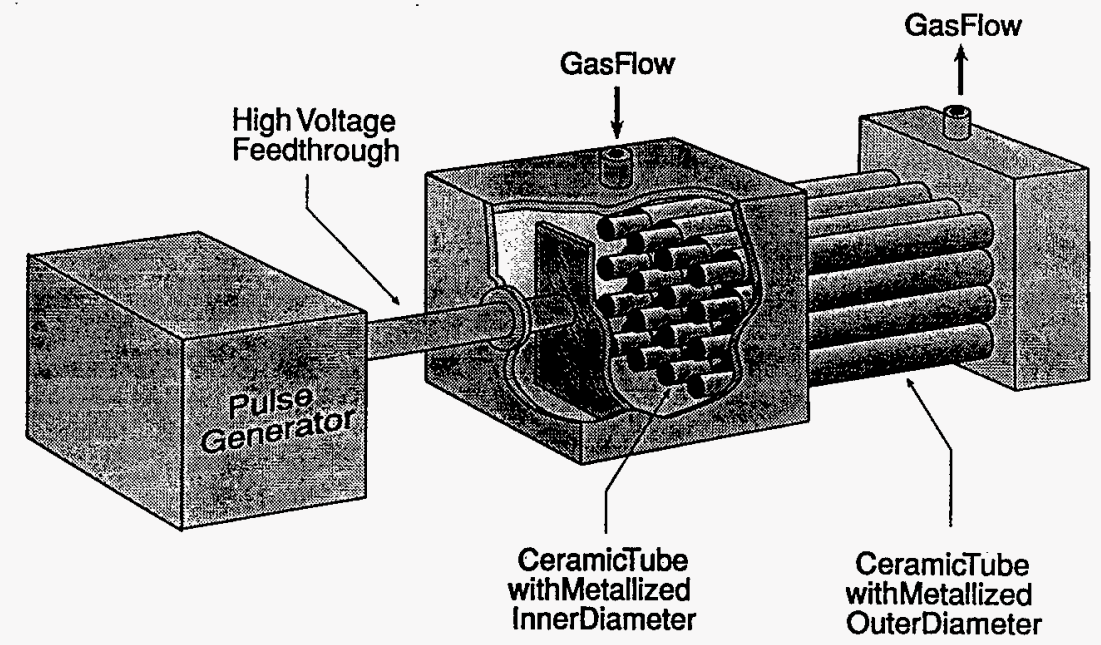

Figure 3: Modular NTP-reactor scaling using cylindrical barrier-discharge reactors.

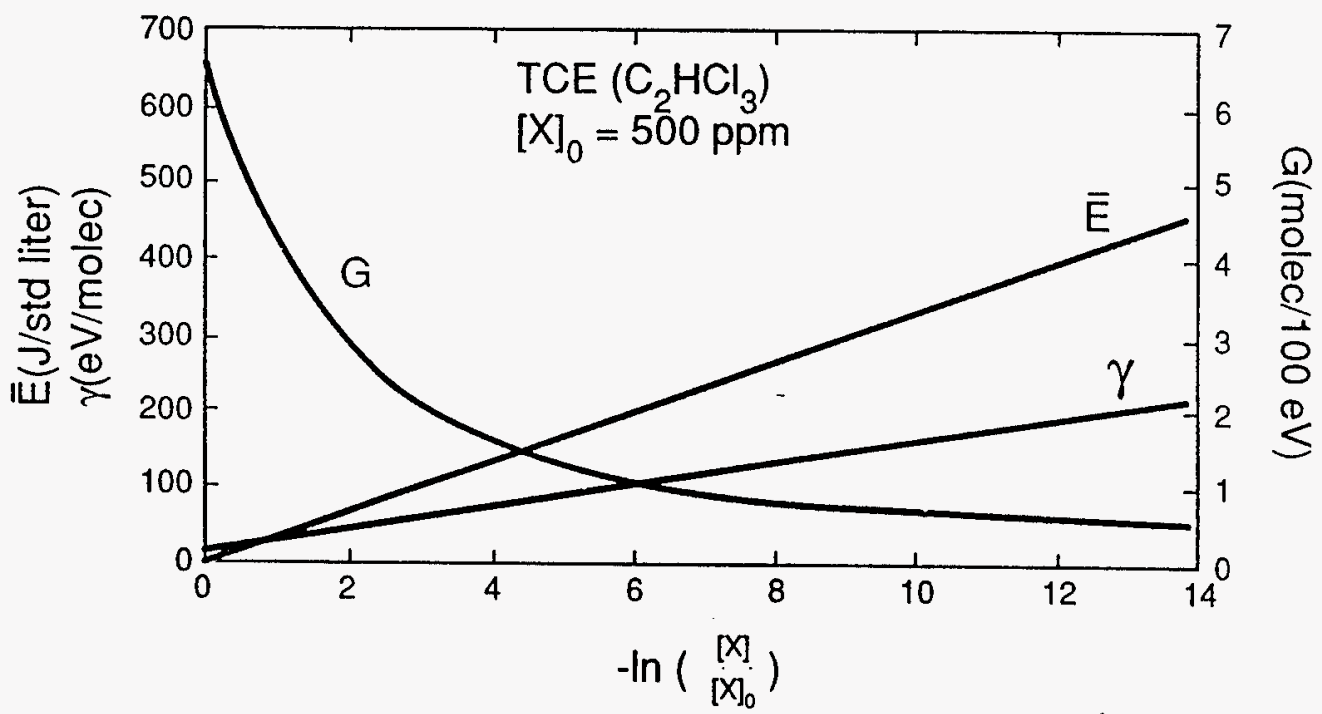

Figure 4: Plasma energy density and figure-of-merit plots for the representative chlorinated solvent TCE, under the model conditions of 80:20 Ar-O2 gas mixture and $\beta=33 \mathrm{~J} /$ lit. A $\beta$-value of approximately $50 \mathrm{~J} /$ lit is typical of nitric oxide (NO) in air, using electrical discharges. As the degree of removal increases, the energy density and energy cost per molecule removed increase. 


\section{Appendix}

\section{High-Temperature, Ceramic Double-Dielectric-Barrier Non-Thermal Plasma Cell Summary Test Results}

In using the modular scaling approach, several identical reactor modules are combined in parallel to achieve a higher capacity. Actual engine exhaust emissions streams containing $\mathrm{NO}_{\mathrm{x}}$ are likely to be characterized by relatively high gas temperatures (e.g., perhaps in the range $300-500 \mathrm{C}$ ). To provide a prototype for a modular system, we have constructed and initially tested a cylindrical, ceramic-dielectric, silent electrical discharge NTP cell. This design is intended to provide a more robust plasma cell, capable of operating at the elevated temperatures likely to be encountered in actual field tests on diesel motor-generator or JETC exhausts.

The figure below illustrates the modular prototype cell. It is constructed of ceramic tubes (alumina), which are metalized to provide the necessary electrodes. This particular cell is approximately $5 \mathrm{~cm}$ in diameter and $76 \mathrm{~cm}$ in length (without the gas manifolds and feedthroughs). The specific energy deposited in the plasma is determined using a combination of high voltage probe and charge-measuring capacitor.

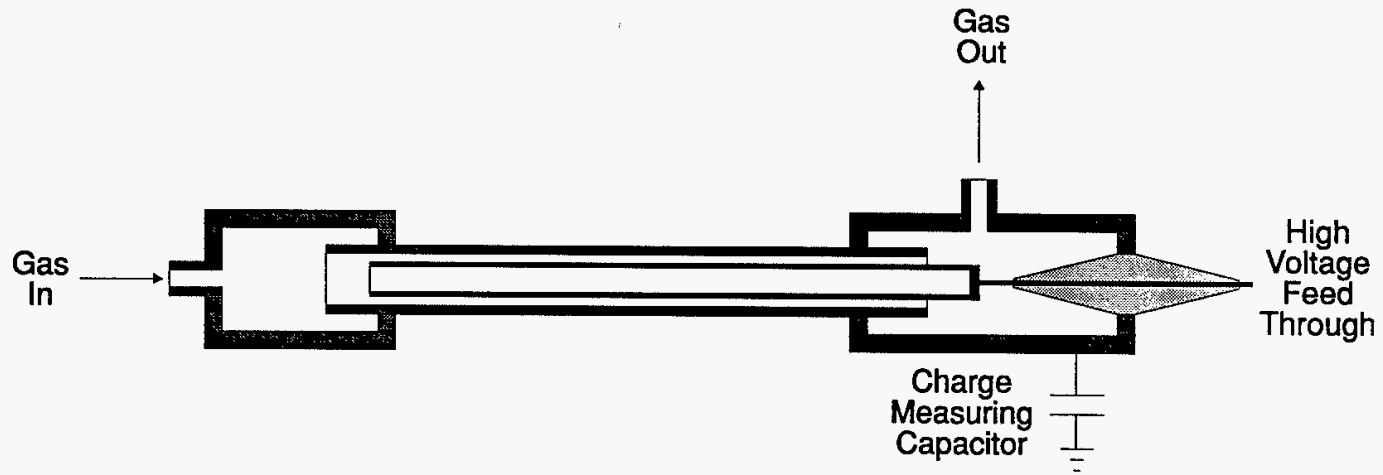

The cell was characterized at different temperatures and power levels, using different feed gases. The summary results are presented below. It should be emphasized that these are preliminary results - no attempt has been made to optimize the performance of the prototype.

At the highest operating temperature attempted $(300 \mathrm{C})$, a power level of $100 \mathrm{~W}$ was easily achieved in dry air. Combining this figure with the 5 lit/min gas flow rate gives a plasma specific energy of $1200 \mathrm{~J} / \mathrm{lit}$. Such a specific energy is quite sufficient for removing many VOCs and is a factor of 24 greater than the one e-fold specific energy typically measured for NO removal in electrical-discharge driven NTP reactors ( $\beta$-value of $50 \mathrm{~J} /$ lit). If we assume a requirement for one e-fold removal ( $63 \%$ of NO removed), then the $5 \mathrm{lit} / \mathrm{min}$ flow rate can be easily increased to $120 \mathrm{lit} / \mathrm{min}$ for this unoptimized prototype module.

- The cell was initially run in open air with $5 \mathrm{lit} / \mathrm{min} \mathrm{N}_{2}$ at $200 \mathrm{~W}(4 \mathrm{kHz})$. Within $10 \mathrm{~min}$, the temperature on the outside surface of the cell rose to $82 \mathrm{C}$ until the power supply shut down. It 
appears that with only a thin layer of nickel for an electrode, the heat transfer from the discharge is lower than with thick electrodes (perhaps due to the thermal mass). After that, the discharge was very unstable at $4 \mathrm{kHz}$, so the electrical drive circuit was adjusted and the cell was run at $1 \mathrm{kHz}$ and $100 \mathrm{~W}$.

- At approximately $100 \mathrm{C}$ data was taken for nitrogen, dry air, and argon at $5 \mathrm{lit} / \mathrm{min}$. The power was $100 \mathrm{~W}$ for nitrogen and dry air and $20 \mathrm{~W}$ for argon. The power level at which the power supply shut down (most probably due to an arc between the internal high voltage feed and the gas manifold) was $200 \mathrm{~W}$ for nitrogen and air and $30 \mathrm{~W}$ for argon.

- The temperature was raised to approximately $200 \mathrm{C}$ using the oven and again data was taken for nitrogen, dry air, and argon at $5 \mathrm{lit} / \mathrm{min}$. The power was $100 \mathrm{~W}$ for nitrogen and dry air and $15 \mathrm{~W}$ for argon. The power level at which the power supply shut down (most probably due to an arc between the internal high voltage feed and the gas manifold) was $180 \mathrm{~W}$ for nitrogen and air and $20 \mathrm{~W}$ for argon.

- The temperature was raised further to approximately $300 \mathrm{C}$ using the oven and again data was taken for nitrogen, dry air, and argon at $5 \mathrm{lit} / \mathrm{min}$. The power was $100 \mathrm{~W}$ for nitrogen and dry air and $15 \mathrm{~W}$ for argon. The power level at which the power supply shut down (most probably due to an arc between the internal high voltage feed and the gas manifold) was $140 \mathrm{~W}$ for nitrogen, $160 \mathrm{~W}$ for air, and $18 \mathrm{~W}$ for argon. 


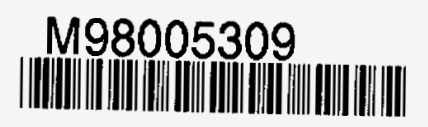

Zeport Number (14) $L A-\cup R=-98-125$

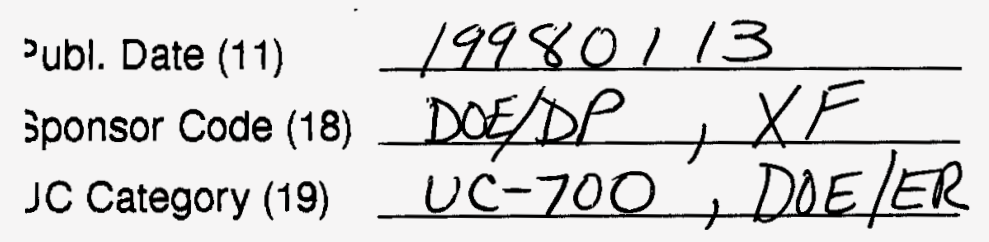

19980706034 